\title{
The Relationship between Psychological Capital and Professional Commitment of Preschool Teachers: The Moderating Role of Working Years
}

\author{
Lee Hsing-Ming ${ }^{1}$, Chou Mei-Ju ${ }^{2}$, Chin Chia-Hui ${ }^{3}$, Wu Ho-Tang ${ }^{4, *}$ \\ ${ }^{1}$ Department of Child Care and Family Studies, Sue-Te University, Taiwan \\ ${ }^{2}$ Department of Early Childhood Education, Shu-Zen Junior College of Medicine and Management, Taiwan \\ ${ }^{3}$ Kaohsiung Municipal Youchang Primary School, Taiwan \\ ${ }^{4}$ Department of Education, National Kaohsiung Normal University, Taiwan
}

Copyright $\bigcirc 2017$ by authors, all rights reserved. Authors agree that this article remains permanently open access under the terms of the Creative Commons Attribution License 4.0 International License

\begin{abstract}
The purpose of this research mainly lies in exploration of influence of psychological capital of preschool teachers on professional commitment, and moderation effect of their working years on the influential relationship between psychological capital and professional commitment. 400 Taiwan preschool teachers took part in this research as the subject to receive measurement of Psychological Capital Questionnaire along with Professional Commitment Scale, and the extracted data underwent analysis of structural equation modeling with use of LISREL software. From the analysis results, it is found that psychological capital of preschool teachers has significantly positive influence on professional commitment, which means that as preschool teachers possess more psychological capital; their professional commitment will get higher correspondingly. In addition, for preschool teachers' working years demonstrates significant moderation effect in the causal correlation of psychological capital to professional commitment, signifying that as working years of preschool teachers increases, influence of their psychological capital on the professional commitment will become better. Finally, based on research findings, we proposed suggestions to preschool teachers, kindergartens, and governmental institutes in how to enhance psychological capital and professional commitment of preschool teachers.
\end{abstract}

Keywords Preschool Teachers, Professional Commitment, Psychological Capital

\section{Introduction}

The change of Taiwan's regulations of early childhood education in recent years, including Early Childhood Education and Care Act, has pushed a more complete preschool education system in spite of causing work stress to preschool teachers. Taken together, in respect to the current educational environment, in the site of early childhood education, in addition to taking good care of children in their class, preschool teachers have to treat heavy and trifle administrative affairs and react to each change in early childhood policies internally. On the other hand, they have to face the parents for parent-teacher communication and endure the pressure of reduction of class number caused by low birth rate. Inevitably, preschool teachers are trapped in the embarrassing situation with wearied body and mind. Even if working in the early childhood environment is full of challenges, some preschool teachers are willing to stay in such work position to take early childhood work as a life-long career. Why they hold a sense of mission and positively devote themselves to this work may resulted from their professional commitment to early childhood work, which refers to loyalty to professional work and the extent of personal identification with such work content in comparison with the relative degree those teachers are engaged in this profession (Brown \& Leigh, 1996; Manheim \& Papo, 2000) $[1,2]$. Actually, in encountering those tangling and complicated educational issues' facets, high level of professional commitment is helpful to raise children's education as well as standard of care.

In the viewpoint regarding psychological capital (PsyCap) was proposed by Luthans, Avolio, Avey, and Norman (2007) [3] to illustrate that content of psychological capital includes four state-like positive psychological resources-self-efficacy, hope, optimism, and resilience, and that psychological capital helps the individual to get adapted to the environment and react to stress, inaugurate the individual's advantageous strengths to overcome the difficulties and pursue a good and happy life. Additionally, when preschool teachers put educational work missions into practice through both mental and physical labor in the 
workplace, if they can raise psychological capital, they will be able to enhance the positive work attitudes and behaviors (Luthans, Youssef, \& Avolio, 2007) [4]. Moreover, relating studies also confirm that psychological capital can raise professional commitment (Avey, Wernsing, \& Luthans, 2008; Luthans, \& Jensen, 2005; Zhong, 2007) [5, 6, 7]; therefore, it is necessary for us to explore the influence of preschool teachers' psychological capital on professional commitment so as to strengthen quality of early childhood education and care.

According to academic hypothesis of House, Kessler and Herzog (1990) [8] that the phenomena in the society would shape the individual's thinking, everyone's habits in daily life are all affected by the "mirror" of this society, everyone would know the self from others' eyes and even construct his/her own power and influential power. Under such conditions, it is extremely possible for psychological capital and professional commitment to be moderated by the variables with control of power resources and implication of influential power. Besides, based on the hypothesis of relational demography assumed by Wiersema and Bantel (1992) [9], under the principle of similarity attraction, which suggests the birds of a feather flock together and like attracts like, psychological capital and professional commitment may be moderated by one of the socio-demographic factors-working years. After all, working years represent one's work time and work experiences in the workplace, and when he/she works longer, it is even more likely for him/her to own psychological capital and professional commitment. In this sense, it is a must for us to discuss the moderation effect of preschool teachers working years on the influential relationship between psychological capital and professional commitment. In short, this research aims to probe into the influential relationship of preschool teachers' psychological capital on professional commitment, and the moderation effect of working years on this relationship.

\section{Review Related Literature}

\subsection{Psychological Capital}

After positive psychology emerged, the observatory vision and research tendency have drawn an extensive range of the public's attention. Positive psychology emphasizes on exploration of advantages and values of human psychology to flourish human life quality and bring human's optimal potential to a full play (Gable \& Haidt, 2005) [10], and to resume the important mission of psychology in regard of helping people grow and be happy, which has aroused remarkable reverberation in the territory of research (Linley \& Joseph, 2004) [11]. However, Luthans's (2002) [12] statement of positive psychology with respect to organizing research context often highlights on "what is wrong with people", while neglects "what is right with people". He further stresses on and strongly agrees that positive experiences can bring up desirable outcomes, and establish various psychological resources, and proposes that application of the research oriented to such positive psychology's constructs to positive organization behavioristics. Meanwhile, he also forcefully initiates exertion of psychological resources that are measurable, developmental, and impactful on performance.

Luthans, Youssef, and et al (2007) [4] propose a more complete definition of psychological capital that he claims to contain four measuring constructs. To begin with, the first construct is self-efficacy that requires the individual to make necessary efforts to successfully carry out challengeable tasks. Followed by the second construct, it is optimism that proceeds positive attribution for the present and future victory. Thirdly, it is the individual's will power and hope that he/she can re-select the approaches to achieve the goals. As for the last one, it relates to resilience that the individual can recover from difficult situation quickly. In the perspective of Luthans, Avolio, and et al (2007) [3], such concept involving psychological capital differs from that in the traditional economic territory; instead, it complies with the standard set up by positive organization behavioristics: 1 . Founded on theories and research; 2. A must of being measured effectively; 3. Unique in organization behavioristics; 4. Developmental and adjustable state-like rather than fixed trait; and 5. Positive impact on work attitudes and work performance (Luthans, Avolio et al., 2007; Luthans \& Youssef, 2004) [3, 13].

In other words, the content of psychological capital relates to the four types of positive psychological power in positive psychology that is unique and can be operated concretely-hope, self-efficacy, resilience, and optimism. Particularly, the four types of positive psychological power are all state-like positive psychological energy with the likelihood of being developed and managed. Otherwise, we can say that psychological capital is the individual's positive psychological resources, which consist of constructs (hope, self-efficacy, resilience, and optimism) or positive psychological state able to be elevated and developed, instead of traits relatively stable and hard to be changed.

\subsection{Impact of Psychological Capital on Professional Commitment}

Definitions of the professional commitment construct range from how one is engaged in carrying out the specific tasks in the work environment to how important for work to play a role in daily life (Brown \& Leigh, 1996; Manheim \& Papo, 2000; Paullay, Alliger, \& Stone-Romero, 1994) [1, 2, 14]. As for this research, professional commitment is considered as a work attitude variable or identification that one has with his/her professional quality in the work field. Professional commitment includes affective commitment, continuance commitment, normative commitment, and other constructs (Meyer, Allen, \& Smith, 1993) [15]. As far as preschool teachers are concerned, affective commitment refers to teachers' identification with and emotional dependence on the profession, leading to the individual's 
autonomic learning and elevation of their professional efficacy. Continuance commitment implies the teachers enjoy concentrating on teaching profession, and are inclined to stay at the present job position. As for normative commitment, it means the teachers' internalization of teaching profession, and being willing to hold an active and positive attitude towards and spirit for participation and performance of teaching profession, while obeying to professional ethics, and obtaining pleasure from work.

Just like Avey, Luthans, and Youssef (2010) [16], Avey, Reichard, Luthans, and Mhatre (2011) [17], Avolio, Gardner, Walumbwa, Luthans and May (2004) [18], and Peterson and Spiker (2005) [19] propose that psychological capital influences outcome variable and research framework, all point out that psychological capital possesses the ability of elevating positive work attitudes and performance. Since professional commitment is exactly one of the work attitude variables, it should be impacted by psychological capital positively.

Here, we try to recount and deduct from the four constructs in psychological capital. To start with self-efficacy, it is a mechanism used by the individual to self-regulate his/her behaviors, according to Bandura's (1991) [20] social cognitive theory of self-regulation. Thus, when the individual's self-efficacy gets higher, his/her self-confidence raises as well, resulting in reaction of self-satisfaction and further presentation of better professional commitment. On the other hand, high self-efficacy means the individual is success-oriented, tends to overcome all difficulties, pursues challengeable work, and so on, all contributing to elevation of professional commitment. In terms of hope, based on hope theory of Snyder (2002) [21], it is highly hoped that the individual to accumulate positive emotional patterns from his/her successful experiences of achieving the goal, enhance agency thinking that makes motivation of goal come true, and scheme pathways thinking to implement the strategies of goal. Moreover, the individual may endeavor to accomplish the goal with guidance of willpower and way power, and generates sense of achievement, under which he/she is encouraged to keep on conducting positive work behaviors with positive work attitudes, leading to high professional commitment. Then, when it comes to optimism, Scheier and Carver's (1985) [22] dispositional optimism is adopted. That is, as the individual's expectation is positive, in the feedback loop of self-regulation, he/she would hold positive work attitudes, and show good professional commitment. Finally, for resilience, as Luthans, Youssef et al (2007) [4] argue that those who have high extent of resilience know better how to maneuver protective factors to resist against stress and adverse situations. In such way, such people will make a step further to surpass obstacles, and present professional commitment through good work attitudes for exhibition of professional commitment. Undeniably, those with high resilience can also face changeable and unsettled environment with employment of strategies to get adapted to such environment with a positive attitude, all raise possibility of strengthening professional commitment. In short, to view psychological capital effect from the respective construct, it is obvious that psychological capital can enhance professional commitment.

\subsection{Moderation Effects of Working Years}

Concerning the research related with psychological capital, they deal either with work attitude variable or with work performance variable as dependent variable, and compatible with above related psychological capital concept for positive impact on work attitudes and work performance. There is few discussion on psychological capital theory on adjustment variable; while Avolio et al(2004) [18] proposed the psychological capital effect model referring to regard work attitude variable as psychological capital effect the intermediary mediator work performance variable. Concerning the current preschool working site, for the less of child birth, non-profit preschool from government support, preschool educators need to hold various activities to show school characteristic to promote admissions. Therefore, for the working years factors, which could be highly possible have strong effect on psychological capital toward professional commitment, which play the intermediary role. For reasonable speculation, working conditions could also be intermediary role. However, in Taiwan public preschool, each preshool educator has similar working burden as private preschool educators. Thus, the crisis for Taiwan preschool is not enough children to be taught in preschool. And Taiwan government chose to cut out few-working-years-experience preschool teachers. Therefore, those experienced preschool educators with more psychological capital could show more professional commitment to deal with the less child crisis, and to ensure their working existence guarantee advantage. In empirical studies on organizational behaviors or organizational psychology, many scholars consider that demographic differences would affect the outcome variables like attitude, behavior, and etc. (Tsui, Egan, \& O'Reilly, 1992; Tsui \& Gutek, 1999) [23, 24]. In addition, in accordance with the theoretical hypothesis suggested by House et al (1990) [8], and Wiersema and Bantel (1992) [9], it is possible for psychological capital and professional commitment to be influenced by one of the socio-demographic factors, work years' moderation effect. This result represents that as one works, provides service, and accumulates work experiences for a longer time, it would be more likely that he/she possesses psychological capital and professional commitment. Particularly, in Chinese workplace culture, the experienced workers often have more power and resources so they can take advantage of those power and resources, just as Sternberg (2000) [25] suggest practical intelligence in everyday life for the experienced workers to make a full use of those resources and power, while Sternberg and Horvath (1999) [26] imply tacit knowledge in professional practice. 
In terms of tacit knowledge or practical intelligence, both can help the experienced workers to accumulate psychological capital and strengthen their identification with professional quality within work field and with how they are engaged in work, so that professional commitment can be enhanced.

\section{Method}

\subsection{Participants}

By means of purposive sampling, we extracted 400 public preschool teachers as the research subject. The teachers' average age is 38.99 years old, average working years is 7.97 , and all are female. To adopt two-stage sampling strategy, for the first stage, in accordance with administrator area to sampling 80 preschools, and for the second stage to randomly sampling preschool educators in accordance with preschool scale. Each preschool is sampled for 2-12 educators for research subject, and the purposive sampling is in accordance with research ethics for the research preschool educators who are willing to correspond with the research.

\subsection{Measures}

\section{(1) Psychological Capital Questionnaire}

We adopted Psychological Capital Questionnaire (PCQ) developed by Lee, Chou, \& Wu (2016) [27] to measure preschool teachers' psychological capital. The preschool teacher's PCQ comprises four subscales with equal weight: self-efficacy, hope, optimism and (4) resilience. Each of these subscales consists of five items with response options on a four-point Likert scale ranging from 1 ('strongly disagree') to 4 ('strongly agree'). To have 150 preschool educator in hand in pre-test, we collect data to have reliability and validity analysis, the result show that $\lambda$ is between 0.73-0.91, Total $\alpha=0.93$, Total Variance $=74.14 \%$. It means that the total questionnaire has quality validity and internal consistency. In Self-efficacy subscale, the items are as "When my job is in bottleneck, I believe I can overcome it"; in Hope subscale, the items are as "I will think a lot of interesting ideas to enhance parent-teacher communication"; In Optimism subscale, the items are as "I have high expectation on the kindergarten's future development"; and in Resilience subscale, the items are as "I can quickly hold my ground in the conflict event happening in the kindergarten."

\section{(2) Professional Commitment Scale}

According to Meyer et al. (1993) [15], Professional Commitment Scale was proposed and divided into three subscales-Affective Commitment subscale, Continuance Commitment subscale, and Normative Commitment subscale. In addition, we consulted literature related to teachers' professional commitment to prepare this scale for measurement of preschool teachers' professional commitment. There are totally 15 items, and each subscale has 5 items. Affective commitment subscale's items are as "Preschool education makes me feel a sense of achievement, so I do not intend to proceed career change"; normative commitment subscale's items are as "I will follow the ethics and norms in preschool educational work". The scale's scoring method utilizes Likert's Four-point Scale to give 1-4 points from "Extremely Disagree", "Disagree", "Agree", and "Extremely Agree". To have pretest for 150 preschool educators, we collect data and have reliability and validity analysis in progress, the result show that $\lambda$ is between $0.64-0.90$, Total $\alpha=0.91$, Total Variance $=75.56 \%$. The total scale has quality validity and internal consistency.

\subsection{Data Analysis}

After receiving the returned formal questionnaires, we checked the answering condition of the questionnaires one by one, and deleted the ineffective ones and those with incomplete information. Then, we coded those effective sample questionnaires obtained from the survey to process by quantitative approach. Following this step, we used the statistic software SPSS and LISREL to conduct statistical analysis. However, before proceeding statistical tests, Harman's Single Factor Test was utilized first to enter all scores of items in the questionnaires on one hand, and employed exploratory factor analysis to elicit un-rotated factor solution for probation into the percentage of explained variance of the first (largest) factor with the purpose of detecting problem of common method variance (CMV). Then, through structural equation modeling, the influential relationship between preschool teachers' psychological capital and professional commitment, together with moderation effect of work years in this relationship were illustrated. At last, according to recommendations provided by Henry and Stone (1994) [28] and Hu and Bentler (1999) [29], we got the following indices of goodness-of-fit: $\mathrm{CFI} \geqq 0.95, \mathrm{RMSEA} \leqq 0.06, \mathrm{AGI} \geqq 0.9, \mathrm{AGFI} \geqq 0.8$.

\section{Results of Analysis}

\section{(1) Common Method Variance Analysis}

Psychological Capital Questionnaire and Professional Commitment Scale, with a total of 35 items, underwent exploratory factor analysis, and the un-rotated factor solution shows there were 7 factors: the percentage of explained variance of the first (largest) factor is $30.05 \%$, less than $50 \%$. As for the 25 items' factor loading in the first factor, only one's factor loading is larger than 0.5. Consequently, this research applied Self-report Scale to collect single subject's cognitive information, and found there was no serious CMV problem, which implies that in the follow-up analysis, CMV will not inflate the observed correlation among variables leading to obscuring the real relationship. In the meantime, such results also show that no confusion of concepts had 
occurred in what we measured in regard of preschool teachers' psychological capital and professional commitment.

\section{(2) Primary Results: Measurement Model}

Using the two-step approach recommended by Kline (2011) [30], prior to estimating the full structural model, we first examined a measurement model with no structural paths to examine model fit. We also used the second order confirmatory factor analysis for the measurement model of psychological capital and professional commitment.

The original hypothesized psychological capital measurement model (the higher-order construct of PsyCap) had the following model fit: $\chi_{(166)}^{2}=239.89, \mathrm{p}=0.00$, RMSEA $=0.04$, CI $90 \%[0.04,0.05]$, GFI $=0.90$, AGFI $=0.88$, $\mathrm{CFI}=0.98$. This final model had adequate model fit. The final measurement model with standardized path estimates is shown in Figure 1.

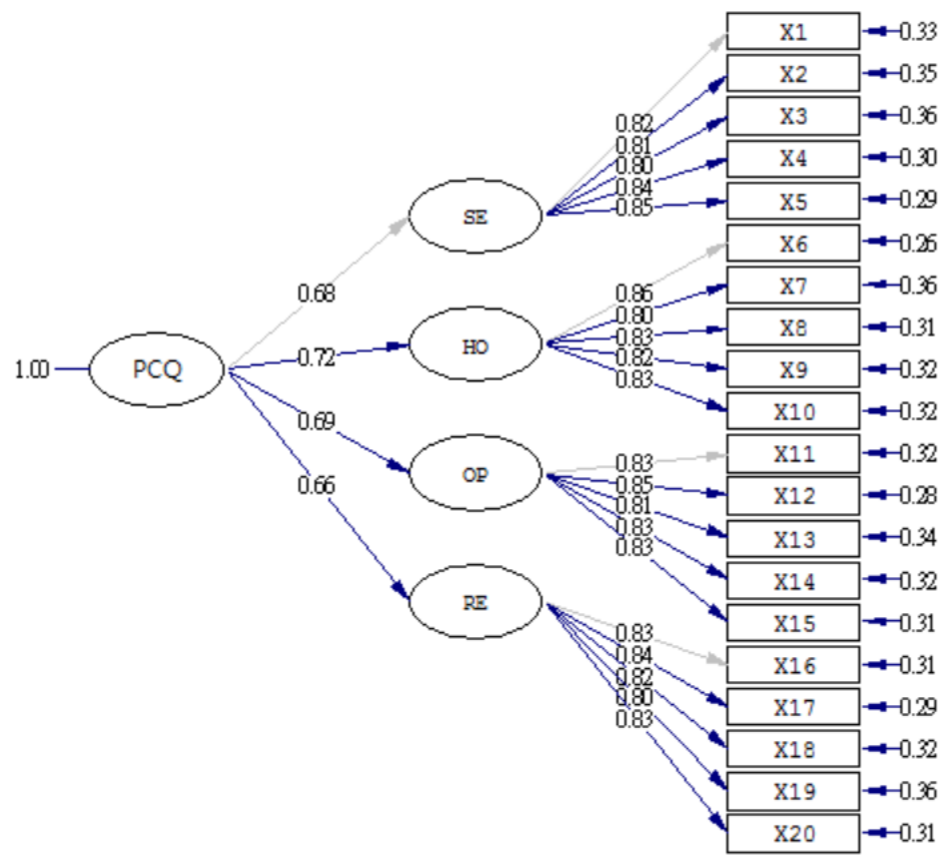

Note: $\mathrm{X} 1$ to $\mathrm{X} 20$ signify items; $\mathrm{PCQ}=$ psychological capital, $\mathrm{SE}=$ self-efficacy, $\mathrm{HO}=$ hope, $\mathrm{OP}=$ optimism and $\mathrm{RE}=$ resilience.

Figure 1. measurement model of psychological capital (standardized solution)

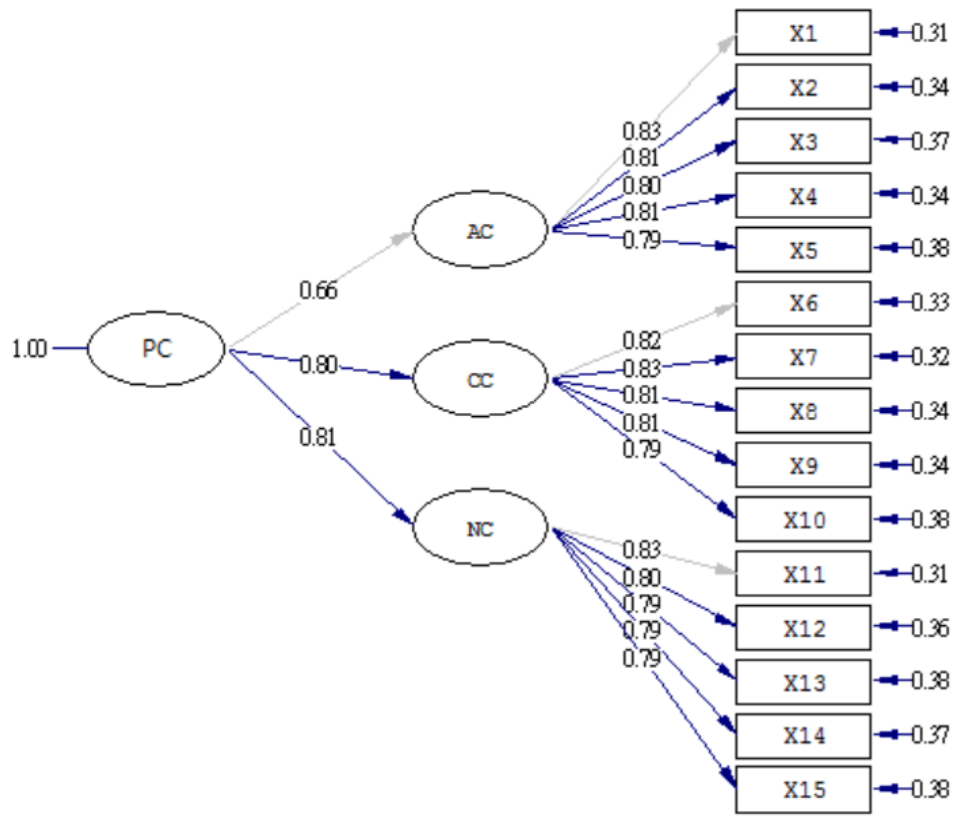

Note: $\mathrm{X} 1$ to $\mathrm{X} 15$ are items, $\mathrm{PC}=$ professional commitment, $\mathrm{AC}=$ affective commitment, $\mathrm{CC}=$ continuance commitment, $\mathrm{NC}=$ normative commitment.

Figure 2. measurement model of professional commitment (standardized solution) 


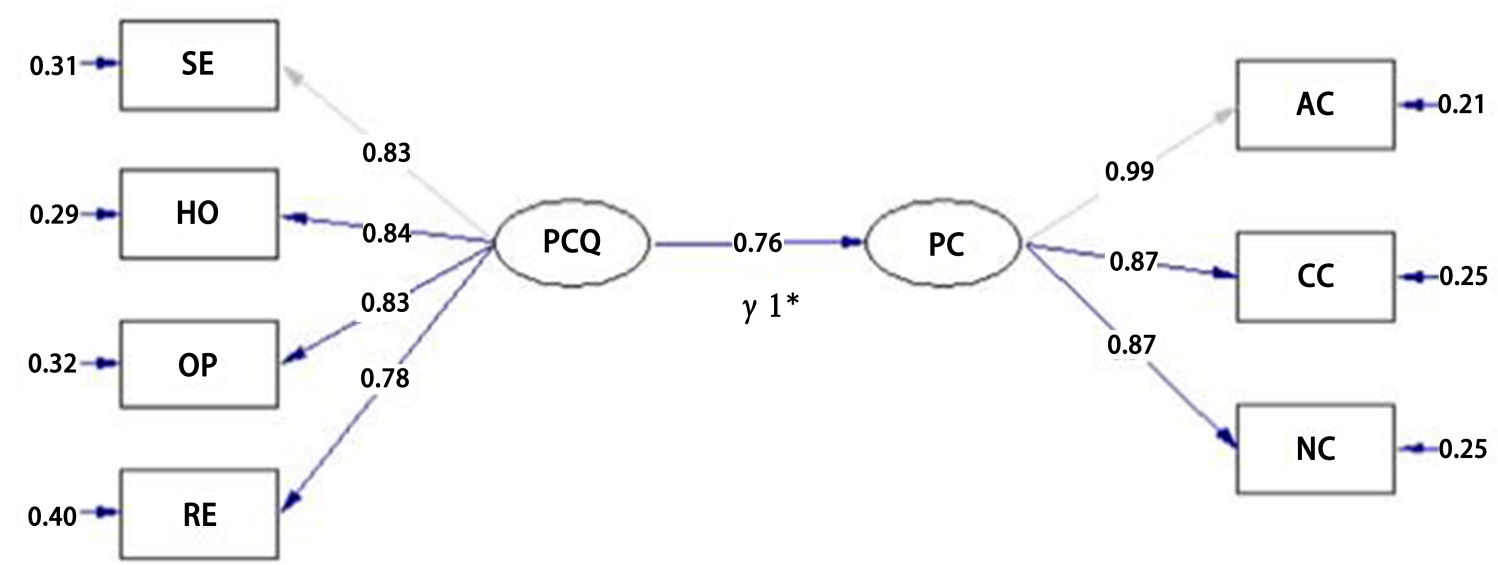

Note: $\mathrm{PCQ}=$ psychological capital, $\mathrm{SE}=$ self-efficacy, $\mathrm{HO}=$ hope, $\mathrm{OP}=$ optimism and $\mathrm{RE}=$ resilience, $\mathrm{PC}=$ professional commitment, $\mathrm{AC}=$ affective commitment, $\mathrm{CC}=$ continuance commitment, $\mathrm{NC}=$ normative commitment.

Figure 3. Original full structural model (standardized solution)

The original hypothesized professional commitment model (the higher-order construct of professional commitment) had the following model fit: $\chi_{(87)}^{2}=141.78$, $\mathrm{p}=0.00 \mathrm{RMSEA}=0.05, \mathrm{CI}_{90}[0.04,0.05], \mathrm{GFI}=0.91$, AGFI $=0.88, \mathrm{CFI}=0.98$. This final model had adequate model fit. The final measurement model with standardized path estimates is shown in Figure 2.

Measurement model is covariant effect of a latent variable and its observed variables. According to the abovementioned confirmatory factor analysis, measurement models all have adequate model fit. Then, when we targeted at the full structural models to conduct latent variable path analysis, the composite score of the measured items of self-efficacy, hope, optimism and resilience can serve as the observed variables of this latent variable for psychological capital. Finally, the composite score measured with affective commitment, continuance commitment, and normative commitment can work as the observed variables of this latent variable for professional commitment.

\section{(3) Relationship between Psychological Capital and Professional Commitment of Preschool Teachers}

Based on literature deduction, this research assumes that relationship exists between psychological capital and professional commitment, while work years are also considered as a moderator. Consequently, we suggest two hypothesized models. One is the original full structural model (Model 1) that shows the relationship between preschool teachers' psychological capital and professional commitment. The other is the alternative model (Model 2), an original full hybrid model related to preschool teachers' psychological capital and professional commitment to raise the effect of this moderator of the working years. Model 1 has the following model fit: $\chi_{(13)}^{2}=23.54, p=0.04$, RMSEA $=$ $0.05, \mathrm{CI}_{90}[0.02,0.07]$, GFI $=0.97$, AGFI $=0.94$, $\mathrm{CFI}=0.99$ ( see Fig. 3). This model 1 has a acceptable model fit. The final model with standardized path estimates is shown in Figure 3.

The Model 2 has the following model fit: $\chi_{(18)}^{2}=19.85$, $\mathrm{p}=0.34, \mathrm{RMSEA}=0.02, \mathrm{CI}_{90}[0.01,0.06], \mathrm{GFI}=0.98$, AGFI $=0.96, \mathrm{CFI}=0.99$. This final model had acceptable model fit. The final model with standardized path estimates is shown in Figure4.

According to the fit indices, we evaluated the two models, and found that Model 1 and Model 2 would well fit the observed data, so Model 1 and Model 2 are acceptable. On the basis of Fig. 3 and LISREL output reports, the path coefficient from psychological capital to professional commitment is $0.76(t=12.58, p<0.05)$. Such results explain why preschool teachers' psychological capital has significantly positive influence on professional commitment. That is to say, as preschool teachers possess more psychological capital; their professional commitment will get higher on the other hand. In addition, consistent with Fig. 4 and LISREL output reports, the path coefficient from work years to psychological capital is $0.57(t=9.58, p<0.05)$, the path coefficient from work years to professional commitment is $0.21(t=3.35, p<0.05)$, and the path coefficient from psychological capital to professional commitment is $0.59(t=8.30, p<0.05)$. In comparison with the path coefficient of the original full structural model, those are all lower, explaining that work years have a moderation effect. In other words, preschool teachers' psychological capital has significantly positive influence on professional commitment, although the extent of influence is associated with work years. Nevertheless, as preschool teachers' work years increases, their influence of psychological capital on professional commitment will get better. In order to concretely demonstrate such moderation effect of working years, we used the median to divide preschool teachers into those with more work years and those with less work years. Aiming at two groups of preschool teachers' influence of psychological capital on professional commitment, regression analysis was applied, as shown in Fig. 5: 




Note: $\mathrm{WY}=$ working years $\mathrm{PCQ}=$ psychological capital, $\mathrm{SE}=$ self-efficacy, $\mathrm{HO}=$ hope, $\mathrm{OP}=$ optimism and $\mathrm{RE}=$ resilience, $\mathrm{PC}=$ professional commitment, $\mathrm{AC}=$ affective commitment, $\mathrm{CC}=$ continuance commitment, $\mathrm{NC}=$ normative commitment.

Figure 4. Alternative model (standardized solution)

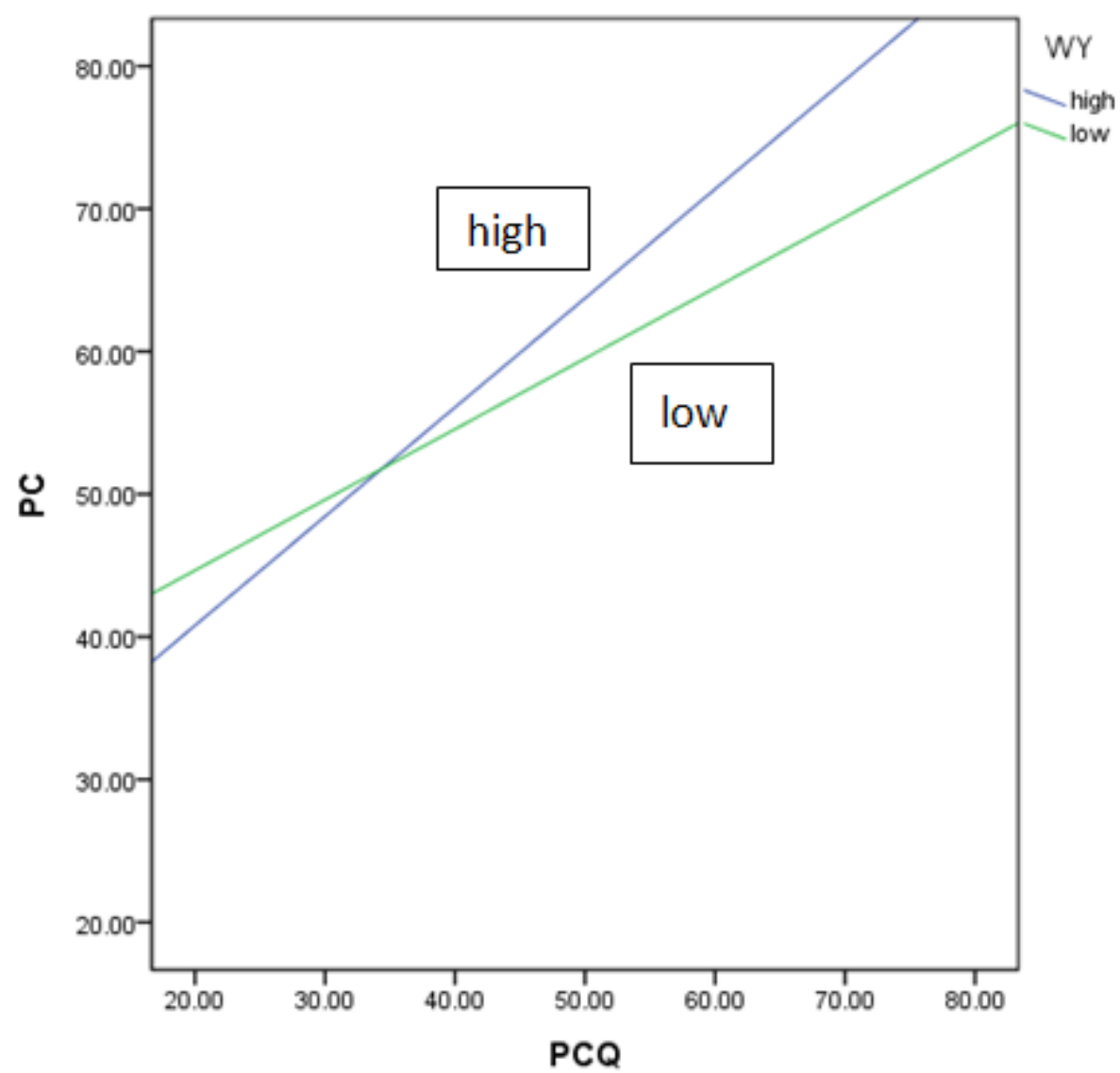

Note: $\mathrm{WY}=$ working years, $\mathrm{PCQ}=$ psychological capital, $\mathrm{PC}=$ professional commitment.

Figure 5. Regression analysis for the experienced and inexperienced preschool teachers' psychological capital's impact on professional commitment 


\section{Discussion}

In accordance with the principle of SEM, during proceeding full structural model, test of measurement model must be done first. Due to full structural model analysis takes the item's composite score as the observed variables, if the measurement model's items' factor loading is too low, the individual item's reliability is poor, then the full structural model analysis will lack empirical foundation. Measures should be reliable and valid; in this case, if the variables are not measured well, the model will not work. Furthermore, by means of adopting one-step approach, the presence of interpretational confounding may not be detected, resulting in fit being maximized at the expense of meaningful interpretability of the constructs. In this research, it is found that psychological capital's and professional commitment's measurement models fit to the data, and can further proceed analysis of evaluation and causal relationship of the full structural model.

From analysis of psychological capital's measurement model, it is found that psychological capital is a higher-order core factor, while hope, resilience, optimism, and self-efficacy may have conceptual independence. However, hope, resilience, optimism, and self-efficacy still make a unique theoretical and measurable contribution to a higher order core construct of psychological capital. As psychological capital contains four components-hope, resilience, optimism, and self-efficacy, such research findings are consistent with the composite elements of psychological capital in literature discussion (Luthans, Youssef et al, 2007) [4].

In analysis of professional commitment's measurement model, we found that professional commitment involves commonalities of affective commitment, continuance commitment, and normative commitment. First, professional commitment is a higher order core construct consisting of affective commitment, continuance commitment, and normative commitment, which is compatible with what recounted in literature review relative to the composite elements of professional commitment (Meyer et al, 1993) [15].

As for the full structural model analysis, it is also found that preschool teachers psychological capital and professional commitment has significantly positive correlation, which means that when the preschool teachers have more psychological capital, they will bring up higher professional commitment. This finding corresponds to what we mentioned in literature review that psychological capital is a psychological resource that casts positive influence on work attitude, work performance, and the like. Certainly, psychological capital can elevate positive work attitude as well as work performance. Since professional commitment is a work attitude variable, it should undeniably be influenced positively by psychological capital (Avey et al, 2010; Avey et al, 2011; Avolio et al, 2004; Peterson \& Spiker, 2005) [16, 17, 18, 19]. Preschool teachers have high level of professional commitment that can contribute to raising the standard of early childhood education and care. At this point, as long as preschool teachers own psychological capital, they will absolutely elevate preschool teachers' professional commitment. As a result, it is indeed a must for us to imitate the measures of Luthans, Avey, Avolio, Norman, and Combs (2006) [31], Luthans, Avey, Avolio, and Peterson (2010) [32] to exert psychological capital intervention for development of preschool teachers' hope, resilience, optimism, and self-efficacy.

In cultivating hope, according to Snyder's (2000) [33] clinical instruction and Luthans and Youssef's (2004) [13] idea of developing hope, we can have preschool teachers practice setting up feasible work plan goals and put it into practice with a variety of approaches. In the process of carrying out the goals, preschool teachers can draw up obstacle removing plan for the potential difficulties on the way of accomplishing the goal. In terms of developing optimism, based on the obstacle removing plan proposed by Luthans (2005) [34], Luthans, and Youssef et al (2007) [4], preschool teachers can do brainstorming with one another for feasible reacting plans, encourage one another, and inspire one another for building up positive expectation, and developing so-called realistic and flexible optimism. As for raising self-efficacy, complying with Bandura's (1997) [35] theory of self-efficacy, on one hand, skills of emotion regulation and social persuasion must be exerted to cultivate preschool teachers' confidence. On the other hand, preschool teachers have to exchange successful experiences or even successful paradigm with one another to raise their self-confidence. For the part of improving resilience, with application of Masten's (2001) [36] suggestions for resilience cultivation, preschool teachers can train themselves to make critical retrospections on the thoughts and emotions generated in adversity, while taking advantage of each personal resource to carry out the planned work goal. Alternatively, schools can encourage preschool teachers to attend in-service trainings for them to understand the preciousness of psychological capital. Above all, the schools can host advanced workshops or educational seminars with relative themes with adoption of practical simulation. For example, by means of Solution-focused brief therapy (SFBT) on the basis of solution-building instead of problem-solving, preschool teachers can learn to transform the negative emotions to positive energy, and use strengths perspective to dissolve the risks. In this way, preschool teachers will be able to experience personally how to make theories and practices coordinate with each other, and elevate the psychological capital of preschool teachers substantially.

The latest research findings show that authentic leadership can raise the employees' psychological capital (Rego, Sousa, Marques, \& Cunha, 2012) [37], which is a process of integrating positive psychological capacities with highly developed organizational context to operate cooperatively. In this process, both the leader and the subordinators will generate intense self-consciousness and self-regulate the 
positive behaviors in order to achieve positive self-development (Avolio et al., 2004; Luthans \& Avolio, 2003) $[18,38]$. Such leadership that emphasizes on sincerity and truth will bring up positive self-development that endow both the leader and the subordinators with psychological capital including self-efficacy, hope, optimism, and resilience, and display positive personal development and self-growth (Cooper, Scandura, \& Schriesheim, 2005; Sparrowe, 2005) [39, 40]. Therefore, authentic leadership can integrate into psychological capital intervention to achieve even better effect.

In alternative model analysis, it is found that working years has a moderation effect. For experienced preschool teachers, their professional commitment is higher than the inexperienced preschool teachers'. Besides, the extent that the experienced preschool teachers' psychological capital raises professional commitment is superior to the inexperienced preschool teachers. This finding implies that, in Chinese workplace culture, the experienced workers often own more power and resources. While in practical situation it really shows the same result, the biggest crisis for Taiwan preschool educators is the lack of children birth, and the government chose to cut out or transfer less experiential preschool educators to correspond with Chinese occupation ethics and culture. On the other hand, more experienced preschool educators might have more working psychological capital to show higher professional commitment to ensure their occupation existential advantage. To take it from another perspective, those experienced preschool educator do have more deep understanding toward preschool, children's parents, and local culture; therefore, they have more significant effect on children's parents and have more problem-solution ability in preschool working site than those less-experience preschool educators. Under this premise, in teacher empowerment activities, the experienced preschool teachers should be encouraged to share the tips to acquire psychological capital and professional commitment through resource exertion, particularly when they are developing personal tacit knowledge or practical intelligence involving hope, resilience, optimism, and self-efficacy.

\section{Conclusions}

Anyway, from "children are the future masters in our nation" viewpoint, we can sense that importance of early childhood education cannot be ignored. To raise the quality of education that our children receive demands preschool teachers' professional commitment, which is interlinked closely with psychological capital. As a result, the Educational units in Taiwan need to help kindergartens open psychological capital intervention programs, and invite the experienced preschool teachers in the teachers' community to share experiences and display simulation for real situation to help elevate the inexperienced preschool teachers' psychological capital. According to the latest research findings, we should inspire the principal in the kindergarten to adopt authentic leadership, which is a positive approach to organizational leadership for raising preschool teachers' psychological capital.

\section{REFERENCES}

[1] S. P Brown, T. W. Leigh. A new look at psychological climate and its relationship to job involvement, effort, and performance, Journal of Applied Psychology, No. 81, 358-368, 1996.

[2] B. Manheim, E. Papo. Differences in organizational commitment and its correlates among professional and nonprofessional occupational welfare workers, Administration in Social Work, No. 23, 119-137, 2000.

[3] F. Luthans, B. J. Avolio, J. B. Avey, S. M. Norman. Positive psychological capital: Measurement and relationship with performance and satisfaction, Personnel Psychology, Vol. 60, No. 3, 541-572, 2007.

[4] F. Luthans, C. M. Youssef, B. J. Avolio. Psychological Capital: Developing the Human Competitive Edge, Oxford University, Oxford, UK, 2007.

[5] J. B. Avey, T. S. Wernsing, F. Luthans. Can positive employees help positive organizational change? Impact of psychological capital and emotions on relevant attitudes and behaviors. The Journal of Applied Behavioral Science, Vol. 44, No. 1, 48-70, 2008

[6] K. W. Luthans, S. M. Jensen. The linkage between psychological capital and commitment to organizational mission: A study of nurses, Journal of Nursing Administration, Vol. 35, No. 6, 304-310, 2005.

[7] L. F. Zhong. Effects of psychological capital on employees' job performance, organizational commitment, and organizational citizenship behavior, Acta Psychologica Sinica, Vol. 39, No. 2, 328-334, 2007.

[8] J. S. House, R. C. Kessler, A. R. Herzog. Age, socioeconomic status, and health, Milbank Quarterly, Vol. 68, No. 3, 383-411, 1990.

[9] M. F. Wiersema, K. A. Bantel. Top management team demography and corporate strategic change, Academy of Management Journal, No. 35, 91-121, 1992 .

[10] S. L. Gable, J. Haidt. What (and why) is positive psychology, Review of General Psychology, Vol. 9, No. 2, 103-110, 2005.

[11] P. A. Linley, S. Joseph. Positive Psychology in Practice. Wiley, Hoboken, 2004.

[12] F. Luthans. Positive organizational behavior: Developing and managing psychological strengths, Academy of Management Executive, Vol. 16, No. 1, 57-75, 2002.

[13] F. Luthans, C. M. Youssef. Human, social, and now positive psychological capital management: Investing in people for competitive advantage, Organizational Dynamics, Vol. 33, No. 2, 143-160, 2004. 
[14] I. M. Paullay, G. M. Alliger, E. F. Stone-Romero. Construct validation of two instruments designed to measure job involvement and work centrality, Journal of Applied Psychology, No. 79, 224-228, 1994.

[15] J. P. Meyer, N. J. Allen, C. A. Smith. Commitment to organization and occupations: Extension and test of a three-component conceptualization, Journal of Applied Psychology, Vol. 78, No. 4, 538-551, 1993.

[16] J. B. Avey, F. Luthans, C. M. Youssef. The additive value of positive psychological capital in predicting work attitudes and behaviors, Journal of Management, No. 36, 430-452, 2010.

[17] J. B. Avey, R. J. Reichard, F. Luthans, K. H. Mhatre. Meta-analysis of the impact of positive psychological capital on employee attitudes, behaviors, and performance, Human Resource Development Quarterly, Vol. 22, No. 2, 127-152, 2011.

[18] B. J. Avolio, W. L. Gardner, F. O. Walumbwa, F. Luthans, D. R. May. Unlocking the mask: A look at the process by which authentic leaders impact follower attitudes and behaviors, Leadership Quarterly, No. 15, 801-823, 2004.

[19] S. J. Peterson, B. K. Spiker. Establishing the positive contributory value of older workers: A positive psychology perspective, Organizational Dynamics, Vol. 34, No. 2, 133-167, 2005

[20] A. Bandura. Social cognitive theory of self-regulation, Organizational Behavior and Human Decision Processes, No. 50, 248-287, 1991.

[21] C. R. Snyder. Hope theory: Rainbows in the mind, Psychological Inquiry, Vol. 13, No. 4, 249-275, 2002.

[22] M. F. Scheier, C. S. Carver. Optimism, coping, and health: Assessment and implications of generalized outcome expectancies, Health Psychology, No. 4, 219-247, 1985.

[23] A. S. Tsui, T. D. Egan, C. A. III. O’Reilly. Being different: Relational demography and organizational attachment, Administrative Science Quarterly, Vol. 37, No. 4, 549-579, 1992.

[24] A. S. Tsui, B. A. Gutek. Demographic Differences in Organizations: Current Research and Future Directions. Lexington Press, New York, 1999.

[25] R. J Sternberg. Practical Intelligence in Everyday Life. Cambridge University Press, Cambridge, 2000.

[26] R. J. Sternberg, J. A. Horvath. Tacit Knowledge in Professional Practice, Lawrence Erlbaum Associates, Mahwah, 1999.
[27] H. M. Lee, M. J. Chou, H. T. Wu. Development and validation of Chinese-version psychological capital questionnaire of preschool teachers, European Journal of Psychological Research, Vol. 3, No. 1, 1-11, 2016.

[28] J. Henry, R. A. Stone. Structural equation model of enduser satisfaction with a computer-based medical information system, Information Resources Management Journal, No. 7 , 21-33, 1994.

[29] L. Hu, P. M. Bentler. Cutoff criteria for fit indexes in covariance structure analysis: Conventional criteria versus new alternatives, Structural Equation Modeling, No. 6, 1-55, 1999.

[30] R. B. Kline. Principles and Pactice of Sructural Euation Mdeling (3rd ed.), Guilford Press, New York, 2011.

[31] F. Luthans, J. B. Avey, B. J. Avolio, S. M .Norman, G. M. Combs. Psychological capital development: toward a micro intervention, Journal of organizational behavior, Vol. 27, No. 3, 387-393, 2006.

[32] F. Luthans, J. B. Avey, B. J. Avolio, S. J. Peterson. The development and resulting performance impact of positive psychological capital, Human resource development quarterly, Vol. 21, No. 1, 41-67, 2010.

[33] C. R. Snyder. Handbook of Hope, Academic Press, San Diego, 2000 .

[34] F. Luthans. Organizational Behavior, McGraw- Hill, New York, 2005

[35] A. Bandura. Self-efficacy: The Exercise of Control. Freeman, New York, 1997.

[36] A. S. Masten. Ordinary magic: Resilience processes in development, American Psychologist, No. 56, 227-239, 2001.

[37] A. Rego, F. Sousa, C. Marques, M. P. e Cunha. Authentic leadership promoting employees' psychological capital and creativity, Journal of business research, Vol. 65, No. 3, 429-437, 2012.

[38] F. Luthans, B. J. Avolio Authentic leadership development. In K. S. Cameron, J. E. Dutton, \& R. E. Quirm (Eds.), Positive organizational scholarship (pp. 241-261). Barrett-Koehler, San Francisco, 2003.

[39] C. Cooper, T. A. Scandura, C. A. Schriesheim. Looking forward but learning from our past: Potential challenges to developing authentic leadership theory and authentic leaders, Leadership Quarterly, No. 16, 474-493, 2005.

[40] R. T. Sparrowe. Authentic leadership and the narrative self, Leadership Quarterly, No. 16, 419-439, 2005. 